\title{
Randomized multicenter phase III study of a modified docetaxel and cisplatin plus fluorouracil regimen compared with cisplatin and fluorouracil as first-line therapy for advanced or locally recurrent gastric cancer
}

\author{
Jinwan Wang • Ruihua Xu · Jian Li • Yuxian Bai · Tianshu Liu • Shunchang Jiao • \\ Guanghai Dai $\cdot$ Jianming Xu $\cdot$ Yunpeng Liu $\cdot$ Nanfeng Fan $\cdot$ Yongqian Shu $\cdot$ Yi Ba \\ Dong Ma $\cdot$ Shukui Qin $\cdot$ Leizhen Zheng $\cdot$ Weichang Chen $\cdot$ Lin Shen
}

Received: 9 June 2014/ Accepted: 29 December 2014/Published online: 21 January 2015

(c) The Author(s) 2015. This article is published with open access at Springerlink.com

\begin{abstract}
Background The V325 study showed that docetaxel, cisplatin, and fluorouracil (DCF) prolonged overall survival (OS) of patients with advanced gastric cancer, but with a high incidence of dose-limiting toxicities. We investigated the efficacy and safety of a modified DCF (mDCF) regimen for Chinese patients with advanced gastric cancer.

Methods Untreated advanced gastric cancer patients randomly received docetaxel and cisplatin at $60 \mathrm{mg} / \mathrm{m}^{2}$ (day 1) followed by fluorouracil at $600 \mathrm{mg} / \mathrm{m}^{2} /$ day (days
\end{abstract}

Jinwan Wang and Ruihua Xu contributed equally to this work.

J. Wang and R. Xu contributed equally to this work.

Electronic supplementary material The online version of this article (doi:10.1007/s10120-015-0457-4) contains supplementary material, which is available to authorized users.

\section{J. Wang}

Cancer Institute and Hospital, Chinese Academy of Medical

Sciences, Beijing, China

R. Xu

Sun Yat-Sen University Cancer Center, Guangzhou, China

\section{J. Li · L. Shen $(\bowtie)$}

Department of Gastrointestinal Oncology, Key Laboratory of Carcinogenesis and Translational Research (Ministry of Education), Peking University Cancer Hospital and Institute, No 52 Fu Cheng Road, Haidian District, Beijing 100142, China e-mail: lin100@medmail.com.cn

Y. Bai

Harbin Medical University Cancer Hospital, Harbin, China

T. Liu

Fudan University Affiliated Zhong Shan Hospital, Shanghai,

China
$1-5$; mDCF regimen) or cisplatin at $75 \mathrm{mg} / \mathrm{m}^{2}$ (day 1) followed by fluorouracil at $600 \mathrm{mg} / \mathrm{m}^{2} /$ day (days $1-5$; CF) every 3 weeks. The primary end point was progression-free survival (PFS). The secondary end points were OS, overall response rate (ORR), time-to-treatment failure (TTF), and safety.

Results In total, 243 patients were randomized to treatment (mDCF regimen 121; CF 122). Compared with CF, the $\mathrm{mDCF}$ regimen significantly improved PFS and OS: the median PFS was 7.2 and 4.9 months, respectively [hazard ratio (HR) $0.58, \log$-rank $P=0.0008$ ], and the median OS was 10.2 and 8.5 months, respectively $(\mathrm{HR}=0.71$, $P=0.0319$ ). Additionally, the $\mathrm{mDCF}$ regimen improved the parameters used as secondary objectives: the ORR was $48.7 \%$ with the $\mathrm{mDCF}$ regimen versus $33.9 \%$ with $\mathrm{CF}$ $(P=0.0244)$; the median TTF was 3.4 months with the mDCF regimen and 2.4 months with $\mathrm{CF}(\mathrm{HR}=0.67$, $P=0.0027)$. Grade 3 and grade 4 treatment-related

\section{S. Jiao - G. Dai}

Chinese PLA General Hospital, Beijing, China

J. Xu

307 Hospital of PLA, Beijing, China

Y. Liu

The First Hospital of China Medical University, Shenyang,

China

N. Fan

Fujian Provincial Cancer Hospital, Fuzhou, China

Y. Shu

Jiangsu Provincial Hospital, Nanjing, China

Y. Ba

Tianjin Medical University Cancer Institute and Hospital,

Tianjin, China 
adverse events occurred in $77.3 \%$ of patients who received the $\mathrm{mDCF}$ regimen versus $46.1 \%$ of patients who received $\mathrm{CF}(P<0.001)$.

Conclusions The mDCF regimen, compared with $\mathrm{CF}$, significantly prolonged PFS and OS and enhanced ORR of Chinese patients with advanced gastric cancer. The $\mathrm{mDCF}$ regimen achieved efficacy comparable to that of DCF but with fewer toxicities, which is appropriate for the Chinese population.

Keywords Advanced gastric cancer - Modified docetaxel and cisplatin plus fluorouracil regimen - Progression-free survival · Overall survival · Safety

\section{Introduction}

Gastric cancer is the fourth most frequent malignancy and the second leading cause of cancer-related mortality. Since the early stages of the disease are often asymptomatic, it is frequently diagnosed at an advanced stage [1, 2].

In the treatment of advanced gastric cancer, no chemotherapy combination has been accepted as the gold standard [1]. Regimens based on 5-fluorouracil (5-FU) and/or cisplatin have been shown to improve survival only modestly in patients in whom advanced gastric cancer is diagnosed [3, 4]. Furthermore, there are few high-quality clinical studies and no internationally accepted standard treatment regimen for patients with gastric cancer in China, which accounts for the $47 \%$ of global new gastric cancer cases $[1,2]$.

Docetaxel has demonstrated activity against gastric cancer both as monotherapy and as a combination with other chemotherapeutic agents, especially when given together with cisplatin and 5-FU [5-7]. The phase II/III V325 study showed that the addition of docetaxel to a cisplatin and 5-FU $(\mathrm{CF})$ regimen significantly improved the time to progression and the overall survival (OS) in untreated advanced gastric cancer patients [5]. However, all patients receiving docetaxel, cisplatin, and 5-FU (DCF; docetaxel at $75 \mathrm{mg} / \mathrm{m}^{2}$ and cisplatin at $75 \mathrm{mg} / \mathrm{m}^{2}$ plus 5 -FU at $750 \mathrm{mg} / \mathrm{m}^{2}$ ) experienced at least one treatmentemergent adverse event. Despite enrollment of a young

\section{Ma}

Guangdong General Hospital, Guangzhou, China

S. Qin

PLA Cancer Center of Bayi Hospital, Nanjing, China

\section{Zheng}

Xin Hua Hospital Affiliated to Shanghai Jiao Tong University School of Medicine, Shanghai, China

W. Chen

Suzhou University Affiliated First Hospital, Suzhou, China population (median age 55 years) with a good functional status (Eastern Cooperative Oncology Group performance status of $0-1$ ), treatment-related grade 3 or grade 4 treatment-emergent adverse events occurred in $69 \%$ of patients. Grade 3-4 neutropenia, febrile neutropenia, and diarrhea were seen in 82, 29, and $19 \%$ of patients, respectively [8]. Similar high rates of grade 3 and grade 4 neutropenia and gastrointestinal adverse events were reported in other clinical trials using the same regimen [7]. As a consequence, the toxicity profile of the DCF regimen has limited the use of this combination.

To achieve the same efficacy with fewer adverse effects, several studies testing various modified DCF (mDCF) regimens have been conducted [9-18]. In a retrospective study that enrolled 54 patients with advanced gastric cancer, an $\mathrm{mDCF}$ regimen consisting of lower doses of DCF (docetaxel at $60 \mathrm{mg} / \mathrm{m}^{2}$, cisplatin at $60 \mathrm{mg} / \mathrm{m}^{2}$, and $5-\mathrm{FU}$ at $600 \mathrm{mg} / \mathrm{m}^{2}$ ) showed efficacy similar to that of the DCF regimen [OS and progression-free survival (PFS) were 10.7 and 6.8 months, respectively] [19]. The incidence of grade 3 and grage 4 toxicities was lower than with the DCF regimen, and grade 3-4 neutropenia was reported in only $4 \%$ of the patients. In a study performed in 107 patients with locally advanced or metastatic gastric cancer, the same mDCF regimen was compared with DCF and was also associated with a lower incidence of grade 3-4 toxicities (grade 3-4 neutropenia reported in $48.3 \%$ of the patients in the DCF arm vs $13.6 \%$ of the patients in the mDCF regimen arm) while maintaining a similar activity (PFS of 9.9 months vs 8.6 months; OS of 7.4 months vs 6.5 months; $P>0.05$ ) [14].

However, there is still lack of randomized controlled studies on $\mathrm{mDCF}$ regimens in patients with advanced gastric cancer, especially in China. Therefore, on the basis of the above-mentioned studies that showed a lower incidence of toxicities for an $\mathrm{mDCF}$ regimen consisting of docetaxel at $60 \mathrm{mg} / \mathrm{m}^{2}$, cisplatin at $60 \mathrm{mg} / \mathrm{m}^{2}$, and $5-\mathrm{FU}$ at $600 \mathrm{mg} / \mathrm{m}^{2}$, we designed a clinical trial to investigate the efficacy and safety of an mDCF regimen in chemotherapynaïve advanced gastric cancer patients in China.

\section{Patients and methods}

Study design and treatment

This study was a multicenter, prospective, randomized, open-label, phase III trial (NCT00811447). It was conducted to compare the efficacy and safety of the dosage-modified DCF regimen versus $\mathrm{CF}$ regimes in patients with advanced gastric cancer or gastroesophageal junction cancer.

Random assignment was centralized and stratified for center, liver metastases, prior gastrectomy, Karnofsky 
performance status (KPS) (80 or above vs below 80 ), and weight loss during the previous 3 months (5\% or less vs more than $5 \%$ ). Eligible patients were randomly assigned (1:1) to receive either docetaxel (Taxotere; Sanofi-Aventis, Paris, France) at $60 \mathrm{mg} / \mathrm{m}^{2}$ (1-h intravenous infusion) plus cisplatin at $60 \mathrm{mg} / \mathrm{m}^{2}$ (1- to 3 -h intravenous infusion) on day 1 , followed by $5-\mathrm{FU}$ at $600 \mathrm{mg} / \mathrm{m}^{2} /$ day (continuous intravenous infusion) for 5 days ( $\mathrm{mDCF}$ regimen) or cisplatin at $75 \mathrm{mg} / \mathrm{m}^{2}$ on day 1 followed by 5-FU at $600 \mathrm{mg} / \mathrm{m}^{2} /$ day for 5 days (CF regimen). Treatment was given in 3-week cycles. During the study, the dose modification criteria were predefined and were based on toxicities. All patients received appropriate hydration and patients in the mDCF regimen arm also received corticosteroids as premedication. Treatment continued until there was disease progression, unacceptable toxicity, death, or consent withdrawal.

The study was approved by the Institutional Review Board of each participating center or the competent authority and the Ethics Committee. The study was conducted in full accordance with the International Conference on Harmonization Good Clinical Practice guidelines and the Declaration of Helsinki. All patients provided written informed consent before any study procedure.

\section{Patient population}

Major inclusion criteria were age 18 years or older; histologically proven gastric or gastroesophageal junction adenocarcinoma; measurable and/or assessable metastatic disease according to Response Evaluation Criteria In Solid Tumors (RECIST) version 1.0 [20]; KPS higher than 70; no prior palliative chemotherapy; 6 weeks or longer following radiotherapy and 3 weeks or longer following surgical intervention; and adequate hepatic, renal, and hematologic function. The major exclusion criteria were other concomitant cancer, neuropathy, brain or leptomeningeal involvement, uncontrolled significant comorbid conditions, or if the patient could not comprehend the purpose of the study and could not comply with its requirements.

\section{Study assessment}

Assessments were performed at the time of the enrollment, and every 6 weeks after the administration of the study drugs. Tumor response was defined as complete response (CR), partial response (PR), stable disease (SD), and progressive disease (PD) according to RECIST and was assessed by the investigators. PFS was measured from the day of the random assignment to the first evidence of progression or death. Survival was defined as the time from the date of random assignment to the date of death from any cause. The tumor response rate (RR) was calculated per treatment arm as the proportion of randomized patients having a confirmed best response of PR or CR. Time-totreatment failure (TTF) was defined as the time from the date of randomization to the date of failure (progression, death, or any other causes of treatment discontinuation). Toxicities were evaluated weekly and were graded according to the National Cancer Institute of Canada Common Toxicity Criteria (NCIC-CTC) version 3.0 [21].

Statistical analysis

The primary objective was to demonstrate superiority of DCF compared to CF in terms of PFS using a stratified logrank test with a two-sided $5 \%$ significance level. We considered that the superiority would have been proven if the $\mathrm{mDCF}$ regimen prolonged the PFS by at least 1.9 months compared with CF. This calculation was based on the results of the V325 study, which showed a PFS of 3.7 months with CF and 5.6 months with DCF [5]. We estimated that at least 187 events should be observed in 200 patients to have an $80 \%$ power to reject the null hypothesis. Assuming a loss to follow-up of $15 \%$, we calculated that 240 subjects (120 subjects per treatment arm) were required. The study duration was 30 months, and subject accrual occurred in the first 18 months. The analysis of the primary end point was performed in the intention-to-treat population.

The major secondary end points included OS, overall RR (ORR), TTF, and safety. The Kaplan-Meier curve was used to describe survival data. PFS and OS were compared between arms using the stratified log-rank test as well as the Cox proportional hazards model. ORRs were compared using Fisher's exact test. Safety analyses were based on the safety sets defined as all patients who received at least one dose of the study medication and had at least one follow-up safety assessment. Safety analyses included all adverse events, as well as the events possibly or probably related to study medication, and were performed using Fisher's exact test.

For the stratified log-rank test, the parameters used for the stratification of the randomization were included as covariates in the model: liver metastasis (yes, no), prior gastrectomy (yes, no), weight loss in the past 3 months (5\% or less, more than $5 \%$ ) and KPS (80 or above, below 80 ).

\section{Results}

Patient demographic and baseline characteristics

A total of 243 patients from 15 centers across China were eligible and were randomized to treatment (mDCF regimen 
Fig. 1 The Consolidated Standards of Reporting Trials (CONSORT) diagram depicting the trajectory of the trial. AJCC American Joint Committee on Cancer, $A L T$ alanine transaminase, $A S T$ aspartate transaminase, $C F$ cisplatin and fluorouracil, $m D C F$ modified docetaxel, cisplatin, and 5-fluorouracil regimen, $U N L$ upper normal limit

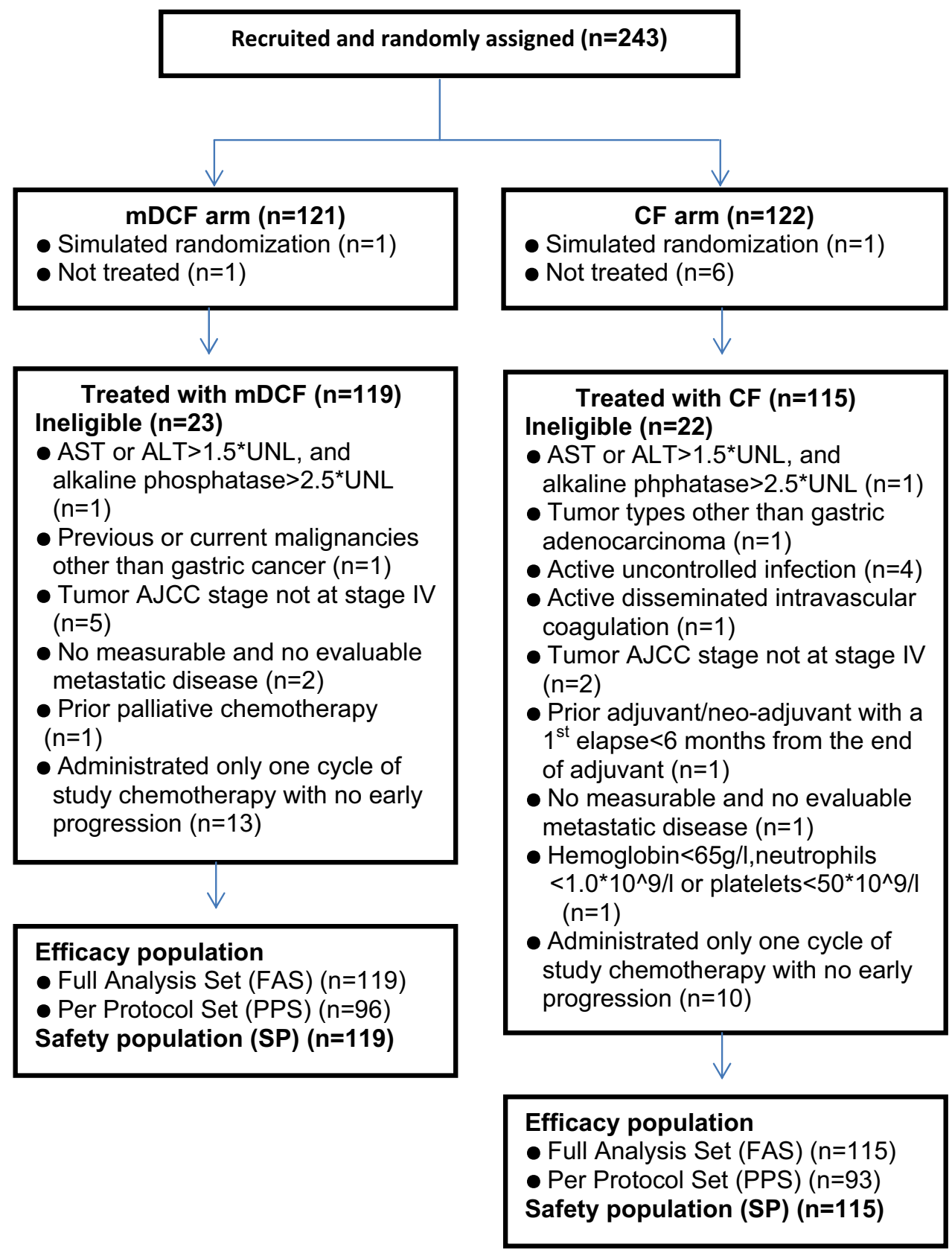

121; CF 122); 234 patients received the allocated combination regimen (mDCF regimen 119; CF 115) and were included in the full-analysis population. The study flow chart is shown in Fig. 1. Patients in both arms were comparable in terms of demographic and baseline characteristics (Table 1).

Treatment characteristics

Overall, 591 cycles of mDCF regimen treatment (median five cycles; range 1-13 cycles) and 464 cycles of $\mathrm{CF}$ treatment (median four cycles; range 1-12 cycles) were administered. The median duration of therapy was 17 weeks with the mDCF regimen (range 3-46 weeks) and 12.6 weeks with CF (range 3-40 weeks). The median actual and relative dose intensities of docetaxel were $288.7 \mathrm{mg} / \mathrm{m}^{2}$ (range $58-769 \mathrm{mg} / \mathrm{m}^{2}$ ) and $91.0 \mathrm{mg} / \mathrm{m}^{2}$ (range $61-104 \mathrm{mg} / \mathrm{m}^{2}$ ), respectively. The median actual and relative dose intensities of 5-FU and cisplatin were similar in both arms. Overall, 79.0 and $68.7 \%$ of the patients in the $\mathrm{mDCF}$ regimen arm and the $\mathrm{CF}$ arm, respectively, had a cycle delay or a dose reduction (Table S1). Myelosuppression was the commonest reason for cycle delay in both treatment arms and the main reason 
Table 1 Demographic and baseline characteristics of study participants $(n=234)$
AJCC American Joint

Committee on Cancer, $C F$

cisplatin and 5-fluorouracil,

$D C F$ docetaxel, cisplatin, and

5-fluorouracil, $H R$ hazard ratio, KPS Karnofsky performance status

a The range (years) is given in parentheses.

b The standard deviation is given in parentheses.

c The range (months) is given in parentheses.

d Adjuvant/neoadjuvant

\begin{tabular}{|c|c|c|c|}
\hline Characteristics & $\mathrm{DCF}(n=119)$ & $\mathrm{CF}(n=115)$ & Total $(n=234)$ \\
\hline Male sex & $81(68.1 \%)$ & $88(76.5 \%)$ & $169(72.2 \%)$ \\
\hline \multicolumn{4}{|l|}{ Age } \\
\hline Median $\left(\right.$ years) ${ }^{\mathrm{a}}$ & $56.6(19-80)$ & $55.5(33-74)$ & $56.1(19-80)$ \\
\hline$<65$ years & $99(83.2 \%)$ & $96(83.5 \%)$ & $195(83.3 \%)$ \\
\hline$\geq 65$ years & $20(16.8 \%)$ & $19(16.5 \%)$ & $39(16.7 \%)$ \\
\hline \multicolumn{4}{|l|}{ Duration of gastric cancer (months) } \\
\hline Mean $^{\mathrm{b}}$ & $8.82(18.25)$ & $6.89(13.70)$ & $7.87(16.17)$ \\
\hline Median $^{c}$ & $0.69(0-124.3)$ & $0.62(0-64.4)$ & $0.68(0-124.3)$ \\
\hline \multicolumn{4}{|l|}{ KPS } \\
\hline$\geq 80$ & $115(96.6 \%)$ & $108(93.9 \%)$ & $223(95.3 \%)$ \\
\hline$<80$ & $4(3.4 \%)$ & $7(6.1 \%)$ & $11(4.7 \%)$ \\
\hline \multicolumn{4}{|l|}{ Weight loss in prior 3 months } \\
\hline$\leq 5 \%$ & $70(58.8 \%)$ & $65(56.5 \%)$ & $135(57.7 \%)$ \\
\hline $5-10 \%$ & $28(23.5 \%)$ & $28(24.3 \%)$ & $56(23.9 \%)$ \\
\hline$>10 \%$ & $21(17.6 \%)$ & $22(19.1 \%)$ & $43(18.4 \%)$ \\
\hline \multicolumn{4}{|l|}{ Primary tumor site } \\
\hline Gastroesophageal junction & $20(16.8 \%)$ & $29(25.2 \%)$ & $49(20.9 \%)$ \\
\hline Fundus & $12(10.1 \%)$ & $9(7.8 \%)$ & $21(9.0 \%)$ \\
\hline Antrum & $44(37.0 \%)$ & $41(35.7 \%)$ & $85(36.3 \%)$ \\
\hline Body & $43(36.1 \%)$ & $37(32.2 \%)$ & $80(34.2 \%)$ \\
\hline Other & $13(10.9 \%)$ & $6(5.2 \%)$ & $19(8.1 \%)$ \\
\hline Unknown & $1(0.8 \%)$ & $2(1.7 \%)$ & $3(1.3 \%)$ \\
\hline \multicolumn{4}{|l|}{ Disease status } \\
\hline Recurrent & $30(25.2 \%)$ & $26(22.6 \%)$ & $56(23.9 \%)$ \\
\hline Metastatic & $89(74.8 \%)$ & $89(77.4 \%)$ & $178(76.1 \%)$ \\
\hline \multicolumn{4}{|l|}{ Histology } \\
\hline \multicolumn{4}{|l|}{ Adenocarcinoma } \\
\hline Moderate differentiation & $19(16.0 \%)$ & $18(15.7 \%)$ & $37(15.8 \%)$ \\
\hline Moderate-low differentiation & $6(5.0 \%)$ & $8(7.0 \%)$ & $14(6.0 \%)$ \\
\hline Low differentiation & $60(50.4 \%)$ & $55(47.8 \%)$ & $115(49.1 \%)$ \\
\hline Unknown differentiation & $25(21.0 \%)$ & $27(23.5 \%)$ & $52(22.2 \%)$ \\
\hline Signet ring cell cancer & $20(16.8 \%)$ & $15(13.0 \%)$ & $35(15.0 \%)$ \\
\hline Mucous adenocarcinoma & $3(2.5 \%)$ & $4(3.5 \%)$ & $7(3.0 \%)$ \\
\hline Other & $1(0.8 \%)$ & $1(0.9 \%)$ & $2(0.9 \%)$ \\
\hline \multicolumn{4}{|l|}{ AJCC staging } \\
\hline III & $5(4.2 \%)$ & $2(1.7 \%)$ & $7(3.0 \%)$ \\
\hline IV & $113(95.0 \%)$ & $112(97.4 \%)$ & $225(96.2 \%)$ \\
\hline Unknown & 0 & $1(0.9 \%)$ & $1(0.4 \%)$ \\
\hline \multicolumn{4}{|l|}{ No. of organs involved } \\
\hline 1 & $52(43.7 \%)$ & $56(48.7 \%)$ & $108(46.2 \%)$ \\
\hline 2 & $37(31.1 \%)$ & $42(36.5 \%)$ & $79(33.8 \%)$ \\
\hline$>2$ & $28(23.5 \%)$ & $16(13.9 \%)$ & $44(18.8 \%)$ \\
\hline \multicolumn{4}{|l|}{ Prior therapy } \\
\hline Radiotherapy & $1(0.8 \%)$ & 0 & $1(0.4 \%)$ \\
\hline Surgery & $46(38.7 \%)$ & $39(33.9 \%)$ & $85(36.3 \%)$ \\
\hline Palliative & $9(19.6 \%)$ & $10(25.6 \%)$ & $19(22.4 \%)$ \\
\hline Curative & $30(65.2 \%)$ & $27(69.2 \%)$ & $57(67.1 \%)$ \\
\hline Other & $7(15.2 \%)$ & $2(5.1 \%)$ & $9(10.6 \%)$ \\
\hline Chemotherapy $^{\mathrm{d}}$ & $23(19.3 \%)$ & $22(19.2 \%)$ & $45(19.2 \%)$ \\
\hline
\end{tabular}


for docetaxel dose reduction $(2.9 \%)$. None of these patients in either arm received concomitant radiotherapy.

At the cutoff date (the date when the last patient completed the study treatment), all patients had stopped the study treatment and 31.09 and $41.74 \%$ of the patients in the mDCF regimen arm and the $\mathrm{CF}$ arm, respectively, discontinued treatment because of disease progression, whereas the remaining patients in both arms discontinued treatment for other reasons. As of the study cutoff date, 37.0 and $39.1 \%$ of the patients in the mDCF regimen arm and the $\mathrm{CF}$ arm, respectively, received further antitumor therapy. Six patients $(5.0 \%)$ and five patients $(4.3 \%)$ in the mDCF regimen arm and the $\mathrm{CF}$ arm, respectively, underwent tumor-related surgery. Additionally, five patients $(4.2 \%)$ and nine patients $(7.8 \%)$ in the $\mathrm{mDCF}$ regimen arm and the $\mathrm{CF}$ arm, respectively, received tumorrelated radiotherapy. Moreover, 31.9 and $35.7 \%$ of the patients in the $\mathrm{mDCF}$ regimen arm and the $\mathrm{CF}$ arm, respectively, received tumor-related drug therapy after the end of the study treatment.

\section{PFS and OS}

The median duration of the follow-up was 22.5 months in the mDCF regimen arm and 23.5 months in the CF arm. The Kaplan-Meier distribution of PFS in the intention-totreat population is shown in Fig. 2a. The median PFS was 7.2 months $[95 \%$ confidence interval (CI) 5.5-8.8 months] in the mDCF regimen arm and 4.9 months (95\% CI 4.5-6.0 months) in the CF arm. The difference in PFS between the two study arms was statistically significant (log-rank test, $P=0.0008$ ) with a hazard ratio $(\mathrm{HR})$ of 0.58 (95\% CI 0.42-0.80), and a risk reduction of $42 \%$. Subgroup analyses revealed that PFS was significantly longer for the following groups: age below 70 years (HR 0.64; $95 \%$ CI 0.48-0.86), male gender (HR 0.62; $95 \%$ CI 0.44-0.87), liver metastasis (HR 0.46; $95 \%$ CI 0.29-0.72), no prior gastric surgery (HR $0.57 ; 95 \%$ CI $0.40-0.81$ ), weight loss more than $5 \%$ (HR 0.56; $95 \%$ CI 0.36-0.87), KPS $\geq 80$ (HR 0.64; $95 \%$ CI 0.47-0.86), and distal primary tumor site (HR 0.58; $95 \%$ CI 0.40-0.84) (Fig. 2b).

The Kaplan-Meier distribution of OS is shown in Fig. 2c. The median OS was 10.2 months (95\% CI 8.6-11.9 months) in the $\mathrm{mDCF}$ regimen arm and 8.5 months (95 \% CI 7.1-9.5 months) in the CF arm. The difference between the two arms was statistically significant (log-rank test, $P=0.0319)$, with an HR of $0.71(95 \%$ CI $0.52,0.97$ ) and a risk reduction of $29 \%$.

\section{ORR and TTF}

The ORR (CR and PR) was $48.7 \%$ (95 \% CI 39.5-58.1) in the $\mathrm{mDCF}$ regimen arm, which was statistically significantly higher than that of the CF arm [33.9\% (95\% CI 25.3-43.3)] (Fisher's exact test, $P=0.0244$ ). The median overall response duration was 7.1 months $(95 \% \mathrm{CI}$ 5.5-9.4 months) in the mDCF regimen arm and 5.0 months (95\% CI 3.5-8.7 months) in the CF arm (Fig. 3a). The difference between the two arms was not statistically significant (log-rank test, $P=0.3757$ ), with an $\mathrm{HR}$ of 0.801 (95\% CI 0.489-1.312) and a risk reduction of $19.9 \%$.

The median TTF was 3.4 months $(95 \%$ CI 2.5-3.8 months) in the mDCF regimen arm and 2.4 months (95\% CI 2.3-3.2 months) in the CF arm (log-rank test, $P=0.0027)$, with an HR of 0.674 (95\% CI 0.518-0.876) and a risk reduction of $32.6 \%$ (Fig. 3b), suggesting a statistically significant benefit in favor of the mDCF regimen.

\section{Safety}

The main medication-related treatment-emergent hematologic and gastrointestinal adverse events are summarized in Table 2 . Grade 3 and grade 4 neutropenia was significantly more frequent in patients in the $\mathrm{mDCF}$ regimen arm $(60.5 \%)$ than in patients in the CF arm (9.6\%), as were febrile neutropenia $(12.6 \%$ in $\mathrm{mDCF}$ regimen arm vs $0 \%$ in $\mathrm{CF}$ arm) and neutropenic infection (1.8\% in $\mathrm{mDCF}$ regimen arm vs $0 \%$ in $\mathrm{CF}$ arm). Grade 3 or grade 4 treatment-emergent serious adverse events related to docetaxel were recorded in only $2.5 \%$ of the patients. The number of discontinuations due to a treatment-emergent adverse event was similar in both arms. Four deaths (3.4\%) occurred within 30 days of the last infusion in the mDCF regimen arm and one death $(0.9 \%)$ occurred within 30 days of the last infusion in the CF arm. The number of deaths occurring beyond 30 days of the last infusion was $85(71.4 \%)$ in the mDCF regimen arm and $90(78.3 \%)$ in the $\mathrm{CF}$ arm. The main cause of death was disease progression in both arms $(70.6 \%$ in the mDCF regimen arm vs $76.5 \%$ in the $\mathrm{CF}$ arm).

\section{Discussion}

Docetaxel as a single agent has proven effective as firstline treatment in advanced gastric cancer in phase II clinical trials [22, 23]. The phase III V325 study has further demonstrated the clinical benefit of docetaxel [5]. The current study was conducted in previously untreated Chinese patients with advanced gastric adenocarcinoma using reduced doses of DCF. Consistent with previous findings [22], the mDCF regimen significantly improved PFS, OS, and RR, suggesting that the inclusion of docetaxel in the $\mathrm{CF}$ regimen is clinically beneficial to Chinese patients with advanced gastric cancer. 
Fig. 2 a The Kaplan-Meier distribution of progression-free survival (PFS). Patients with advanced gastric adenocarcinoma or adenocarcinoma of the gastroesophageal junction were randomly assigned to receive docetaxel, cisplatin, and 5-fluorouracil $(D C F)$ or cisplatin and 5-fluorouracil $(C F)$. b PFS [hazard ratios $(H R)$ and $95 \%$ confidence intervals $(C I)]$ for selected subgroup analyses. c The Kaplan-Meier distribution of overall survival (OS). KPS Karnofsky performance status, $L C L$ lower confidence limit, $U C L$ upper confidence limit
A

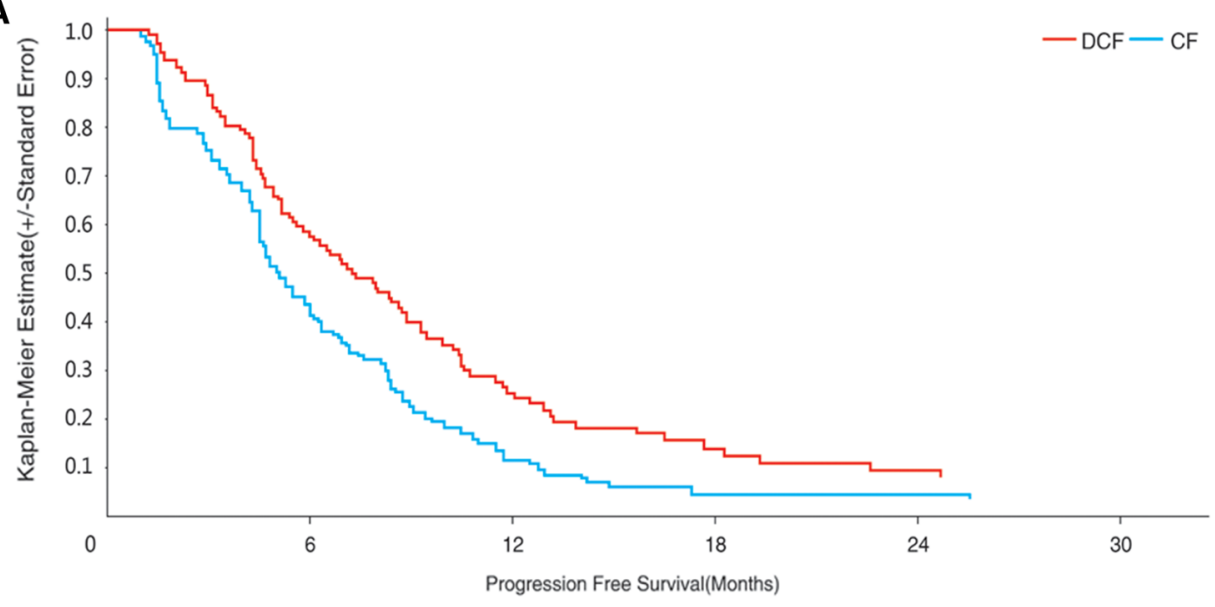

B

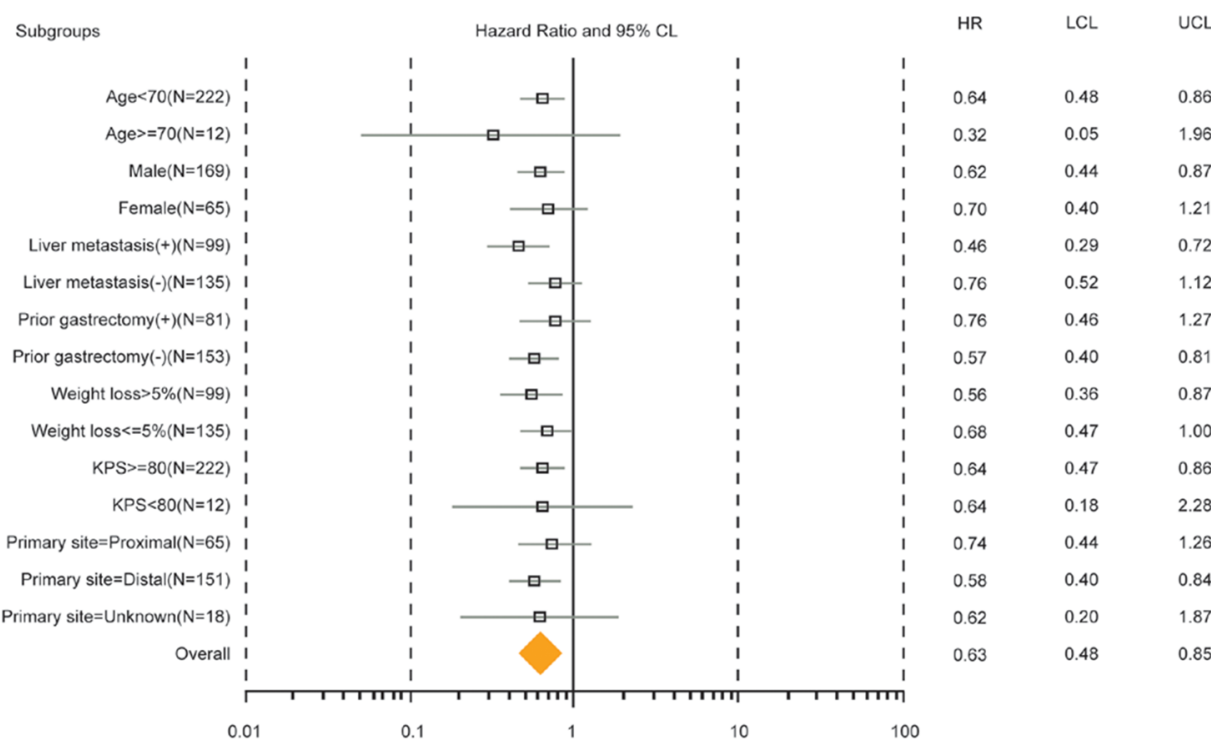

C

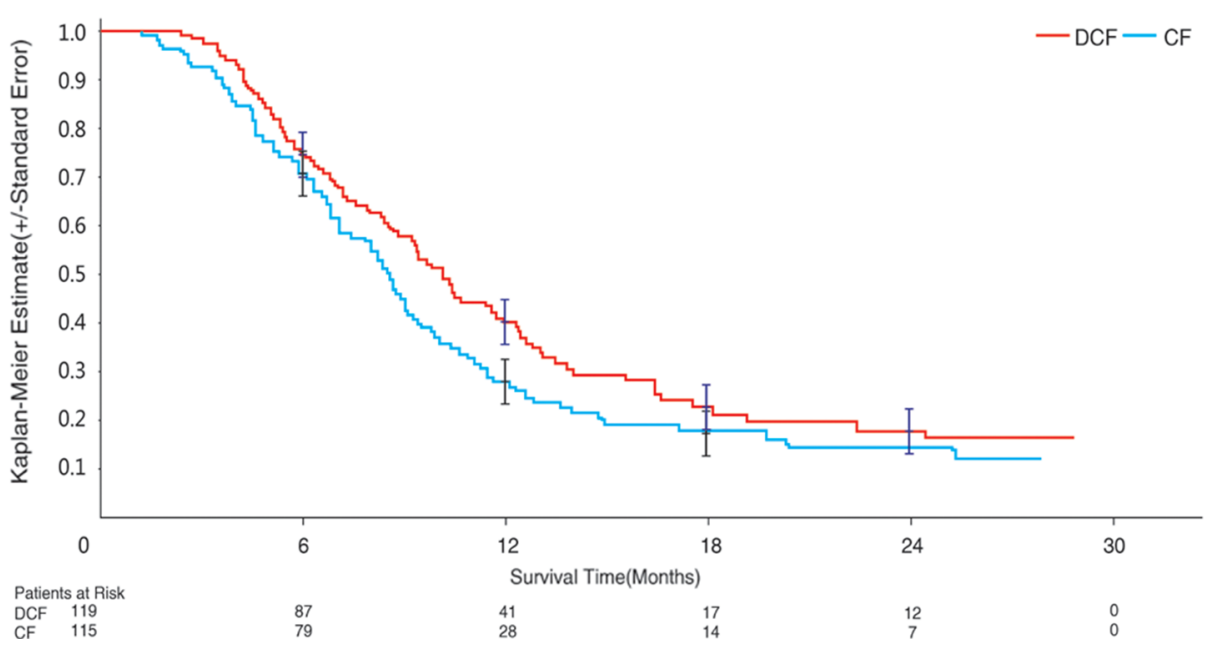

The median PFS was 2.3 months longer in the $\mathrm{mDCF}$ regimen arm compared with the $\mathrm{CF}$ arm, exceeding the preset superiority threshold of 1.9 months for the difference between the study arms and thus meeting the primary end point. Additionally, the $\mathrm{mDCF}$ regimen significantly prolonged the median OS compared with the $\mathrm{CF}$ 
Fig. 3 a The Kaplan-Meier distribution of overall response duration. Patients with advanced gastric adenocarcinoma or adenocarcinoma of the gastroesophageal junction were randomly assigned to receive docetaxel, cisplatin, and 5-fluorouracil $(D C F)$ or cisplatin and 5-fluorouracil $(C F)$. Duration of response was calculated in responders and was defined from the onset of partial response/complete response. b The Kaplan-Meier distribution of the time to treatment failure
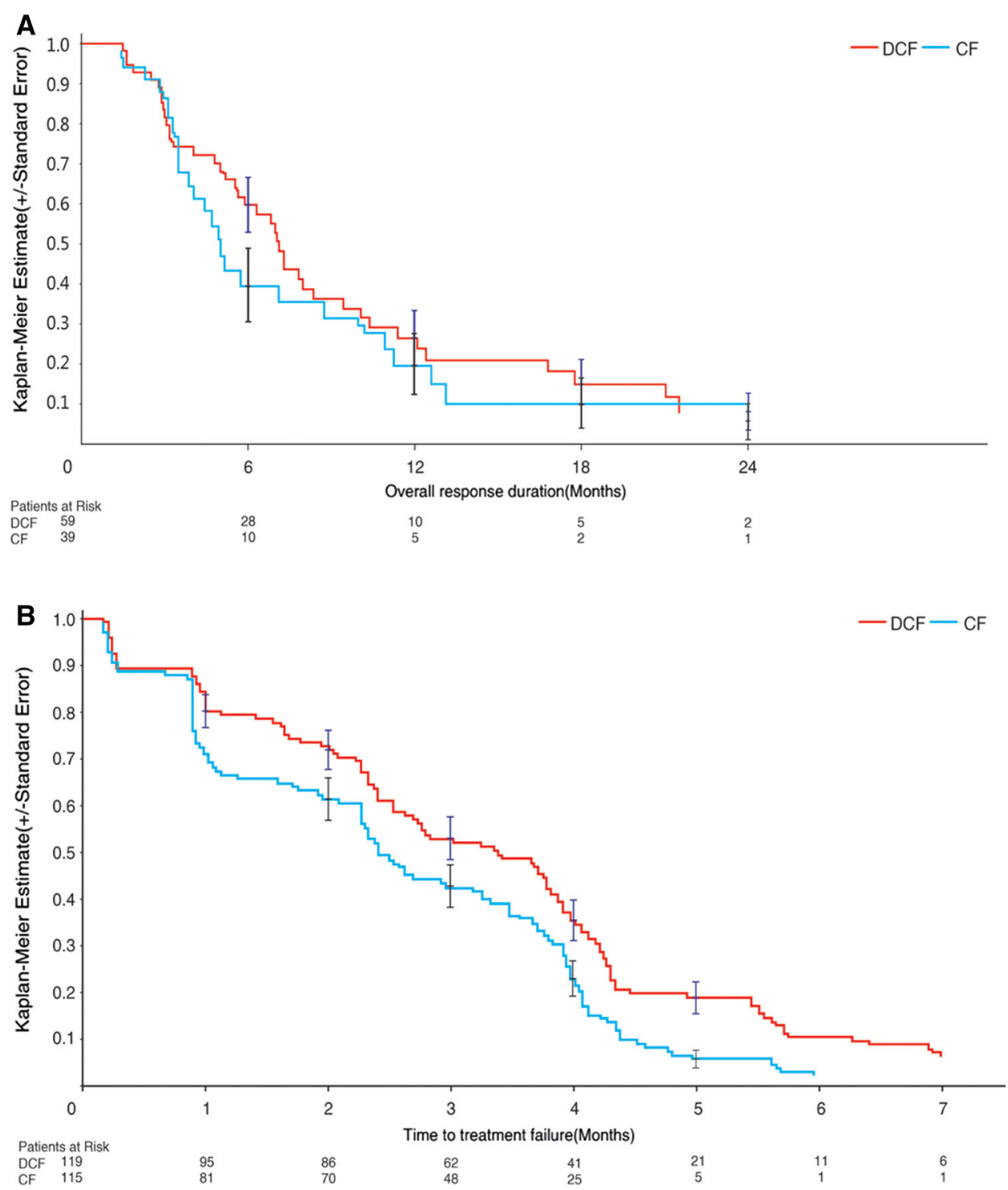

regimen [10.2 months vs 8.5 months, HR 0.71 (95\% CI $0.52-0.97), P=0.0319]$. In terms of the reduction in the risk of death, our results were similar to those of the V325 study [5]. The V325 study enrolled 457 patients with advanced gastric cancer in 16 countries and randomized them to receive either docetaxel at $75 \mathrm{mg} / \mathrm{m}^{2}$ and cisplatin at $75 \mathrm{mg} / \mathrm{m}^{2}$ plus 5 -FU at $750 \mathrm{mg} / \mathrm{m}^{2} /$ day (DCF) or cisplatin at $100 \mathrm{mg} / \mathrm{m}^{2}$ plus 5 -FU at $1,000 \mathrm{mg} / \mathrm{m}^{2} /$ day and showed the efficacy of the DCF combination in patients with advanced gastric cancer [5]. After a median follow-up of 23.4 months, the median OS was 9.2 months in the DCF arm and 8.6 months in the control arm (log-rank test, $P<0.02$ ), with a reduction of $23 \%$ in the risk of death [5]. In our study, the patients assigned to receive the mDCF regimen achieved longer OS than the patients enrolled in the V325 study. Additionally, the ORR in both study arms was higher than in the V325 study $(48.7 \%$ in the mDCF regimen arm vs $30.3 \%$ in the DCF arm; $33.9 \%$ vs. $19.9 \%$ in the $\mathrm{CF}$ arm). These differences may be explained by the higher number of patients with locally advanced cancer enrolled in our study ( $23.9 \%$ vs. $3 \%$ in the V325 study). Additionally the radical surgery, radical radiotherapy, or second-line chemotherapy recommended after chemotherapy in $30 \%$ of patients in our study may have contributed to the prolongation of the OS. Although the OS of 10.2 months was longer than that in the V325 study, it was shorter than that observed in other studies in which patients with gastric cancer were treated with doublets [24-26]. The SPIRITS trial, in which 298 Japanese patients with advanced gastric cancer were randomized to receive either S-1 (Taiho Pharmaceutical, Tokyo, Japan) plus cisplatin or S-1 alone, showed a median OS of 13 months in the S-1 plus cisplatin arm and 11 months in the S-1 alone arm $(P=0.04)$ [24]. In the START trial, which enrolled 639 
Table 2 Hematologic and gastrointestinal toxicities (National Cancer Institute of Canada Common Toxicity Criteria version 1.0)

\begin{tabular}{|c|c|c|c|c|}
\hline \multirow[t]{2}{*}{ Toxicity } & \multicolumn{2}{|c|}{$\operatorname{DCF}(n=119)$} & \multicolumn{2}{|l|}{$\mathrm{CF}(n=115)$} \\
\hline & Grade 3-4 & All grades & Grade 3-4 & All grades \\
\hline \multicolumn{5}{|l|}{ Hematologic toxicities $^{\mathrm{a}}$} \\
\hline Neutropenia & $72(60.5 \%)$ & $94(79.0 \%)$ & $11(9.6 \%)$ & $67(58.3 \%)$ \\
\hline Leucopenia & $62(52.1 \%)$ & $105(88.2 \%)$ & $2(1.7 \%)$ & $74(64.3 \%)$ \\
\hline Anemia & $6(5.0 \%)$ & $40(33.6 \%)$ & $6(5.2 \%)$ & $36(31.3 \%)$ \\
\hline Thrombocytopenia & $2(1.7 \%)$ & $26(21.8 \%)$ & $5(4.3 \%)$ & $37(32.2 \%)$ \\
\hline Febrile neutropenia & $15(12.6 \%)$ & $16(13.4 \%)$ & 0 & $1(0.9 \%)$ \\
\hline \multicolumn{5}{|c|}{ Gastrointestinal toxicities } \\
\hline Stomatitis & $4(3.4 \%)$ & $26(21.8 \%)$ & 0 & $5(4.3 \%)$ \\
\hline Diarrhea & $15(12.6 \%)$ & $57(47.9 \%)$ & 0 & $9(7.8 \%)$ \\
\hline Nausea & $3(2.5 \%)$ & $71.4(85 \%)$ & $8(7.0 \%)$ & $89(77.4 \%)$ \\
\hline Vomiting & $9(7.6 \%)$ & $63(52.9 \%)$ & $13(11.3 \%)$ & $79(68.7 \%)$ \\
\hline
\end{tabular}

$C F$ cisplatin and 5-fluorouracil, $D C F$ docetaxel, cisplatin, and 5-fluorouracil

${ }^{a}$ Patients were assessed for hematologic toxicity if they had one or more cycles with a blood count for the given test between day 2 and the first infusion of the next cycle, and had received no prophylactic treatment during the cycle.

patients from Japan and Korea, the OS was 12.5 months in patients who received $\mathrm{S}-1$ in combination with docetaxel compared with 10.8 months in patients who received S-1 alone [25]. In another phase III trial, published by Boku et al. [26], the median OS was 10.8 months in patients assigned to 5-FU treatment, 12.3 months in those assigned to irinotecan plus cisplatin treatment, and 11.4 months in those assigned to treatment with S-1 alone. The shorter OS in our study as compared with the OS in previous ones described here may be explained by the differences in the frequency of administration of the second-line treatment and which might have favorably influenced the OS in these studies: $35 \%$ (chemotherapy, radiotherapy, and surgery) in our study compared with up to $78 \%$ of the patients assigned to doublets in other studies [24-26]. Thus, although the second-line therapy may have contributed to the prolongation of the OS in our study, the low number of patients receiving second-line therapy was due to the study starting in 2008 when the proportion of second-line treatment acceptance was generally low in China and limited the effect.

It should be noted that we chose the PFS as the main objective of our trial instead of the OS owing to the requirement of the China Food and Drug Administration to have this parameter evaluated as the main objective in clinical trials performed in China before a drug or a regimen obtains marketing approval. The MAGIC study [27] proved that perioperative chemotherapy with a regimen of epirubicine, cisplatin, and continuous 5-FU infusion enhanced the R0 rate (no residual tumor) and prolonged OS. In our study, the mDCF regimen achieved a tumor RR of nearly $50 \%$. Although our sample size was limited and we did not analyze locally advanced cancer patients who received radical surgery after chemotherapy, on the basis of the higher tumor RR, it is worth investigating further whether the mDCF regimen could be used as neoadjuvant chemotherapy.

The clinical benefit of DCF in the V325 study was obtained at the expense of increased toxicity [5], which requires comprehensive toxicity management strategies. As expected, in Chinese advanced gastric cancer patients, the mDCF regimen did not cause any previously unreported treatment-emergent adverse events. Compared with $\mathrm{CF}$, specific adverse events such as leukopenia and diarrhea were more frequent with the $\mathrm{mDCF}$ regimen, but other adverse events such as nausea and dyspepsia were less frequent. This toxicity profile in Chinese advanced gastric cancer patients treated with the $\mathrm{mDCF}$ regimen was similar to that of the V325 study.

Predictably, for docetaxel-containing regimens, the most frequently reported toxicities are hematologic ones. In the V325 study, the frequency of grade 3/4 neutropenia was $82 \%$ and that of febrile neutropenia was $29 \%$ in the DCF arm, whereas in our study, for the mDCF regimen arm, the frequencies of both grade $3 / 4$ neutropenia and febrile neutropenia were lower (60.5 and $13.4 \%$, respectively), indicating that the $\mathrm{mDCF}$ regimen was associated with reduced hematologic toxicities as compared with DCF in the V325 study without compromising efficacy.

Although we have shown good efficacy and acceptable toxicities with the mDCF regimen, we must acknowledge several limitations resulting from the open-label design of our study. Tumor response and PFS were evaluated by investigators, and although much effort has been done to 
limit the bias in the evaluation of these parameters (standardized criteria were used to assess the response and disease progression; tumor evaluation was performed at prespecified time points), the interpretation of the imaging findings may have differed between investigators. Although the blinding of clinical trials is the recommended procedure to prevent systematic bias [28], clinical trials for which the investigational medical product is administered intravenously are often designed as open-label trials, especially in oncology. In our study, the docetaxel added to cisplatin and 5-FU in the $\mathrm{mDCF}$ regimen arm was administered as an intravenous infusion, and this would have made the blinding of the study treatment difficult.

In conclusion, our study demonstrated the superior efficacy in terms of PFS of the $\mathrm{mDCF}$ regimen versus CF as first-line treatment for advanced gastric cancer. The study results document the value of docetaxel in the treatment of Chinese advanced gastric cancer patients, and the $\mathrm{mDCF}$ regimen is comparable in efficacy to DCF used in the V325 study but has a more favorable safety profile.

Acknowledgments The study was funded by Sanofi. The authors are grateful for everyone's effort. Adriana Rusu (XPE Pharma and Science) provided editorial support. The National Natural Science Foundation (81172110) and the Beijing Municipal Science and Technology Commission Program (Z11110706730000) are thanked for their support.

Conflict of interest The authors declare they have no conflict of interest.

Open Access This article is distributed under the terms of the Creative Commons Attribution License which permits any use, distribution, and reproduction in any medium, provided the original author(s) and the source are credited.

\section{References}

1. Shen L, Shan YS, Hu HM, Price TJ, Sirohi B, Yeh KH, et al. Management of gastric cancer in Asia: resource-stratified guidelines. Lancet Oncol. 2013;14:e535-47.

2. Ferlay J, Shin HR, Bray F, Forman D, Mathers C, Parkin DM. Estimates of worldwide burden of cancer in 2008: GLOBOCAN 2008. Int J Cancer. 2010;127:2893-917.

3. Murad AM, Santiago FF, Petroianu A, Rocha PR, Rodrigues MA, Rausch M. Modified therapy with 5-fluorouracil, doxorubicin, and methotrexate in advanced gastric cancer. Cancer. 1993;72:37-41.

4. Pyrhönen S, Kuitunen T, Nyandoto P, Kouri M. Randomised comparison of fluorouracil, epidoxorubicin and methotrexate (FEMTX) plus supportive care with supportive care alone in patients with non-resectable gastric cancer. $\mathrm{Br} \mathrm{J}$ Cancer. 1995;71:587-91.

5. Van Cutsem E, Moiseyenko VM, Tjulandin S, Majlis A, Constenla M, Boni C, et al. Phase III study of docetaxel and cisplatin plus fluorouracil compared with cisplatin and fluorouracil as first line therapy for advanced gastric cancer: a report of the V325 Study Group. J Clin Oncol. 2006;24:4991-7.
6. Allum WH, Blazeby JM, Griffin SM, Cunningham D, Jankowski JA, Wong R, et al. Guidelines for the management of oesophageal and gastric cancer. Gut. 2011;60:1449-72.

7. Chen XL, Chen XZ, Yang C, Liao YB, Li H, Wang L, et al. Docetaxel, cisplatin and fluorouracil (DCF) regimen compared with non-taxane-containing palliative chemotherapy for gastric carcinoma: a systematic review and meta-analysis. PLoS One. 2013;8:e60320.

8. Ajani JA, Moiseyenko VM, Tjulandin S, Majlis A, Constenla M, Boni C, et al. Clinical benefit with docetaxel plus fluorouracil and cisplatin compared with cisplatin and fluorouracil in a phase III trial of advanced gastric or gastroesophageal cancer adenocarcinoma: the V-325 Study Group. J Clin Oncol. 2007;25:3205-9.

9. Tomasello G, Chiesa MD, Buti S, Brighenti M, Negri F, Rovere RK, et al. Dose-dense chemotherapy in metastatik gastric cancer with a modified docetaxel-cisplatin-5-fluorouracil regimen. Tumori. 2010;96:48-53.

10. Ben Aharon I, Purim O, Kundel Y, Brenner R, Gordon N, Sulkes A. The combination of docetaxel, cisplatin, and 5-fluorouracil in advanced gastric cancer: a single-institution experience. Anticancer Drugs. 2012;23:313-20.

11. Lorenzen S, Hentrich M, Haberl C, Heinemann V, Schuster T, Seroneit T, et al. Split-dose docetaxel, cisplatin and leucovorin/ luorouracil as first line therapy in advanced gastric cancer and adenocarcinoma of the gastroesophageal junction: results of a phase II trial. Ann Oncol. 2007;18:1673-9.

12. Park SR, Chun JH, Kim YW, Lee JH, Choi IJ, Kim CG, et al. Phase II study of low-dose docetaxel/fluorouracil/cisplatin in metastatic gastric carcinoma. Am J Clin Oncol. 2005;28:433-8.

13. Chi YHBL, Ren JH, Yang L, Cui CX, Li JL, Wang JW. Phase II clinical study on the modified DCF regimen for treatment of advanced gastric carcinoma. Chin Med J. 2011;124:2997-3002.

14. Inal A, Kaplan MA, Kucukoner M, Isikdogan A. Docetaxel and cisplatin plus fluorouracil compared with modified docetaxel, cisplatin, and 5-fluorouracil as first-line therapy for advanced gastric cancer: a retrospective analysis of single institution. Neoplasma. 2012;59:233-6.

15. Ozdemir NY, Abali H, Oksuzoglu B, Budakoglu B, Uncu D, Guler T, et al. The efficacy and safety of reduced-dose docetaxel, cisplatin, and 5-fluorouracil in the first-line treatment of advanced stage gastric adenocarcinoma. Med Oncol. 2010;27:680-4.

16. Kang SH, Kim JI, Goh PG, Hwang SW, Kwon DS, Nam KW, et al. Docetaxel-cisplatin-5-FU combination chemotherapy as a first-line treatment in patients with metastatic or recurred gastric cancer. Korean J Gastroenterol. 2007;50:157-63.

17. Tebbutt NC, Cummins MM, Sourjina T, Strickland A, Van Hazel $\mathrm{G}$, Ganju V, et al. Randomised, non-comparative phase II study of weekly docetaxel with cisplatin and 5-fluorouracil or with capecitabine in oesophagogastric cancer: the AGITG ATTAX trial. Br J Cancer. 2010;102:475-81.

18. Overman MJ, Kazmi SM, Jhamb J, Lin E, Yao JC, Abbruzzese JL, et al. Weekly docetaxel, cisplatin, and 5-fluorouracil as initial therapy for patients with advanced gastric and esophageal cancer. Cancer (Phila). 2010;116:1446-53.

19. Keskin S, Yıldız I, Sen F, Aydogan F, Kilic L, Ekenel M, et al. Modified DCF ( $\mathrm{mDCF}$ ) regimen seems to be as effective as original DCF in advanced gastric cancer (AGC). Clin Transl Oncol. 2013;15:403-8.

20. Therasse P, Arbuck SG, Eisenhauer EA, Wanders J, Kaplan RS, Rubinstein L, et al. New guidelines to evaluate the response to treatment in solid tumors. European Organization for Research and Treatment of Cancer, National Cancer Institute of the United States, National Cancer Institute of Canada. J Natl Cancer Inst. 2000;92:205-16.

21. National Cancer Institute. Common Terminology Criteria for Adverse Events v3.0 (CTCAE). 2006. http://ctep.cancer.gov/ 
protocolDevelopment/electronic_applications/docs/ctcaev3.pdf. Accessed 7 Oct 2014.

22. Sulkes A, Smyth J, Sessa C, Dirix LY, Vermorken JB, Kaye S, et al. Docetaxel (Taxotere ${ }^{\circledR}$ ) in advanced gastric cancer: results of a phase II clinical trial. EORTC Early Clinical Trials Group. Br J Cancer. 1994;70:380-3.

23. Einzig AI, Neuberg D, Remick SC, Karp DD, O'Dwyer PJ, Stewart JA, et al. Phase II trial of docetaxel (Taxotere) in patients with adenocarcinoma of the upper gastrointestinal tract previously untreated with cytotoxic chemotherapy: the Eastern Cooperative Oncology Group (ECOG) results of protocol E1293. Med Oncol. 1996;13:87-93.

24. Koizumi W, Narahara H, Hara T, Takagane A, Akiya T, Takagi $\mathrm{M}$, et al. S-1 plus cisplatin versus S-1 alone for first-line treatment of advanced gastric cancer (SPIRITS trial): a phase III trial. Lancet Oncol. 2008;9:215-21.

25. Koizumi W, Kim YH, Fujii M, Kim HK, Imamura H, Lee KH, et al. Addition of docetaxel to S-1 without platinum prolongs survival of patients with advanced gastric cancer: a randomized study (START). J Cancer Res Clin Oncol. 2014;140:319-28.

26. Boku N, Yamamoto S, Fukuda H, Shirao K, Doi T, Sawaki A, et al. Fluorouracil versus combination of irinotecan plus cisplatin versus S-1 in metastatic gastric cancer: a randomised phase 3 study. Lancet Oncol. 2009;10:1063-9.

27. Lordick F, Siewert JR. Perioperative Chemotherapie vs. alleinige Chirurgie bei resektablen gastroösophagealen Karzinomen. Chirurg. 2006;77:1166-7.

28. US Department of Health and Human Services, Food and Drug Administration, Center for Drug Evaluation and Research, Center for Biologics Evaluation and Research. Guidance for industry. Clinical trial endpoints for the approval of cancer drugs and biologics. 2007. http://www.fda.gov/downloads/Drugs/Guidances/ ucm071590.pdf. Accessed 8 Dec 2014. 